\title{
Biomass promises: A bumpy road to a renewable economy
}

\author{
Layla Filiciotto* ${ }^{\text {a* }}$ Rafael Luque ${ }^{\mathrm{a}}$ \\ ${ }^{a}$ Departamento de Química Orgánica, Universidad de Córdoba,Edificio Marie Curie (C-3), Ctra Nnal \\ IV-A, Km 396,E14014 Córdoba, España, e-mail: q62alsor@uco.es
}

\begin{abstract}
Biomass conversion strategies have been taking hold of the scientific community agenda in the evolution of renewable chemical and energy industries. Nonetheless, biomass conversion yet presents challenges due to its structural complexity, and high reactivity of the oxygen functionalities. This review aims to indicate the reader the main encountered difficulties in the conversion of plant-derived feedstocks and byproducts/waste, with a focus on the catalytic approaches taken so far and the efforts of our research group into contributing to a future bio-based economy.
\end{abstract}

\section{Introduction}

Since the industrial revolution of the $19^{\text {th }}$ century, petroleum has been the major source of commodity chemicals and energy. The massive exploitation of this traditionally called burning water [1] not only has contributed to polluting each compartment of our planet (i.e. air, water, earth) [2-4], but also increased the occurrence of earthquakes in drilling areas [56]. Furthermore, world energy consumption is constantly increasing, while fossil resources are irreversibly being depleted, compelling the implementation of renewable sources.

After the recent break of record of $\mathrm{CO}_{2}$ levels in the atmosphere [7], a closed carbon cycle and circular economy (i.e. take, make, recycle) are highly desirable for both materials and fuels purposes. Biomass transformation has taken a hold of the scientific community, as well as the different nations' energy agenda 
(e.g. the European environmental research and innovation policy), thanks to its capacity to recycle $\mathrm{CO}_{2}$ during photosynthesis, and production of new bio-feedstocks (Figure 1) [8,9]. Furthermore, thanks to the existence of fast and non-edible growing plants, as well as the development of high-output agricultural technologies, a carbon-neutral cycle can be achieved in short periods of time [10]. A bio-based economy, in particular, becomes advantageous compared to other renewable energies (e.g. wind and solar) thanks to the limited seasonal/day fluctuations, and the possibility of using renewable sources and/or waste as feedstock in the chemical and materials industries.

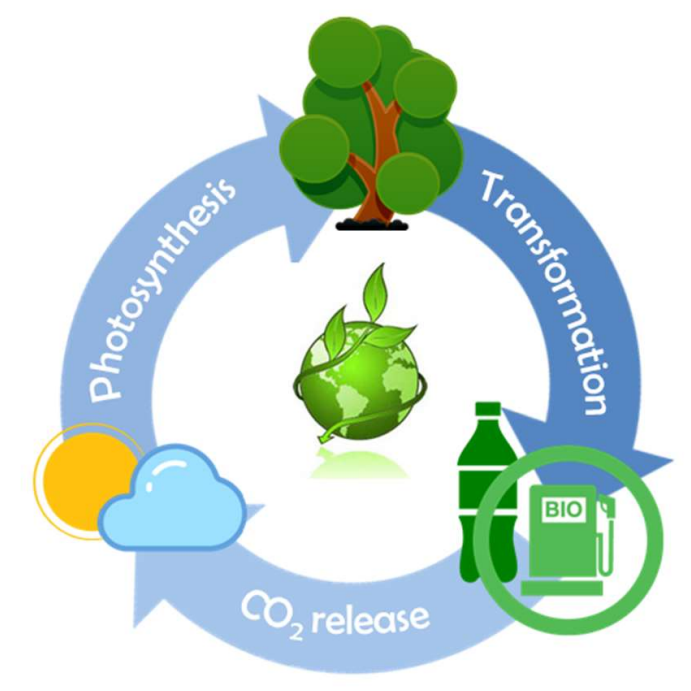

Figure 1. Closed carbon cycle for a bio-based economy.

Biomass is a broader concept that includes various plant-based sources, but not solely. In detail, biomass comprises lignocelluloses, oilseed/sugar/starch crops, acquatic coltures (i.e. algae), and biowastes, such as agricultural/animal/anthropological wastes. Lignocelluloses in particular are not only the most abundant biomass, but also an optimal source of several of compounds: terpenes, carbohydrates, aromatics, and fatty esters. In fact, if possible to isolate and efficiently convert each plant component, every chemical market could be self-sustained with biomass. 
The overall structure of lignocellulosic biomass mainly comprises cellulose (35-50\%), hemicellulose (20$35 \%$ ), and lignin (15-30\%). Cellulose is the source of the plant tensile strength, being a crystalline and linear glucose polymer, thus being an optimal source of this hexose (sugar/carbohydrate). Hemicellulose further strengthens the plant structure by cross-linking with cellulose. Differently from the latter, hemicellulose is a branched random polymers combining a variety of pentose carbohydrates, along with hexoses and uronic acids sugar monomers, becoming an ideal source for sugars such as xylose, mannose, arabinose, galactose, to name a few. Lignin is a rather complex and recalcitrant polyaromatic macromolecule which confers the structural rigidity to the plant wall. Its irregular polymeric structure is comprised of phenylpropane type units, thus being a possible source of a plethora of aromatic molecules, most known being vanillin, eugenol, guaiacol, styrenes, and xylenes. Both fermentation processes and chemical transformations of lignocellulosic biomass can yield to valuable products which can substitute petroleum-platform molecules. In particular, microbial fermentation of cellulosic sugars (i.e. glucose) yields to biofuels (e.g. ethanol) or organic acids such as lactic and succinic, while acid-catalyzed dehydration of hemicelluloses-derived pentoses (i.e. xylose) or cellulose-derived hexoses (i.e. glucose, fructose, and mannose) yields to platform furanics, namely furfural and 5-hydroxymethylfurfural (HMF), respectively. From the hydrolysis of HMF is then obtained the linear and important platform chemical, levulinic acid, which in alcohol media becomes methyl levulinate [11] (Figure 2). 


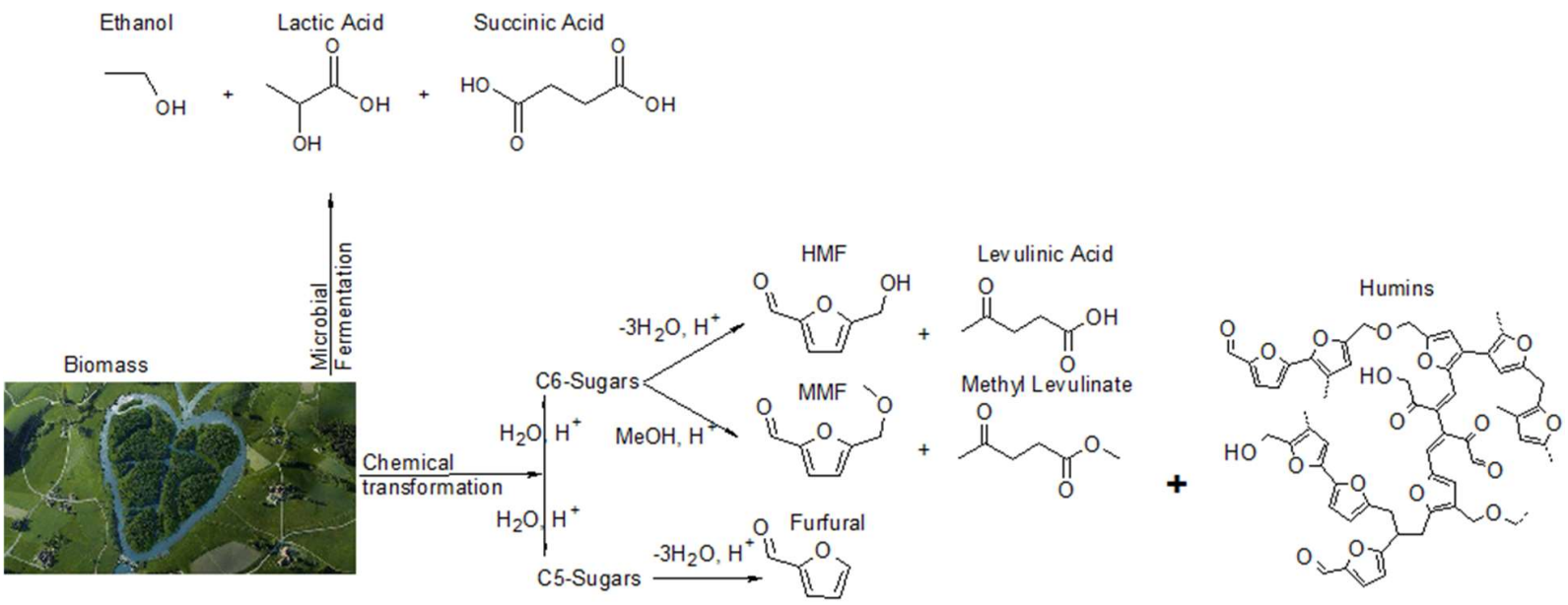

Figure 2. Examples of products from the chemical and microbial transformations of biomass.

The major issues related to the chemical transformation of non-edible biomass (i.e. lignocelluloses) feedstocks lies in its rather complex chemical structure (in particular, lignin) and the large presence of heteroatoms (in particular, oxygen), whose reactivity leads to low atom efficiency and undesired sideproducts, e.g. humins. In particular, humin by-products derive from the thermodynamically-favored random polymerization of the starting molecules (sugars) and products (furanics, levulinics), causing reactor fouling. Less humins can be formed in the presence of co-solvents such as toluene, GVL, and methyl-THF, although complete avoidance of humins is yet inevitable $[12,13]$. The use of larger volumes of solvents would increase the overall cost of the process, both in terms of reactor size and subsequent solvents/product separation (e.g. distillation), thus becoming uncompetitive with the current petroleum-based bulk and fine chemicals market. Thus, upgrading these side-products becomes crucial in order to achieve an economical bio-based market able to substitute traditional fossil feedstocks.

The obstacles in biomass processing are particular relevant when traditional petrol-derived platform chemicals (i.e. aliphatics, olefins, aromatics) are the target product. A shift in the way we perceive platform molecules is indeed due. In order to influence this shift, a list of the top biomass-derived compounds has been first reported by the US Department of Energy in 2004 [14], later revisited by Bozell and Petersen [15]. The identified (group of) 10 molecules (Table 1) can be industrially produced with the current existing 
industries (drop-in technology), and represent promising building blocks for a variety of fine chemicals, specialty materials, and biofuels, to name a few.

Table 1. The 10 promising biomass products identified by Bozell and Petersen [15].

\begin{tabular}{cc}
\hline \multicolumn{2}{c}{ Identified biobased platform chemicals } \\
\hline Ethanol & Succinic acid \\
Furans & Hydroxypropionic acid/aldehyde \\
(Furfural, HMF, FDCA) & \\
Glycerol & Levulinic acid \\
Biohydrocarbons & Sorbitol \\
(Isoprene) & \\
Lactic acid & Xylitol \\
\hline
\end{tabular}

Up to date, mass production of some bio-compounds has already been achieved, as in the Biofine Process which produces levulinic acid, furfural, and formic acid [16]. Advances in the YXY® process developed by Avantium, now part of the joint venture with chemical company BASF, Synvina, aims to the production of an exclusively bio-derived plastic, PEF, based on 2,5-furandicarboxylicacid (FDCA). This plastic possesses superior mechanical and chemical properties, making it a great candidate in substituting petroleum-derived PET $[17,18]$. However, both processes produce recalcitrant/tarry compounds (i.e. humin by-products) prone to reactor fouling. Furthermore, traditional petroleum catalysts might not be active in the processing conditions (i.e. aqueous media, lower operating temperature), thus calling for new catalytic materials.

A bio-based market has the potential to be highly beneficial in environmental, economical, and social terms, although still presenting some adversities. This publication aims to be a compendium of the efforts of the NanoVal research group of Prof. Luque into solving the current challenges of biomass processing and upgrading. Other selected literature examples in biomass conversion technologies are also included for the completion of discussion. 


\section{Catalytic Materials for Biomass Conversion}

The limited solubility of monomeric bio-sugars (which often act as reactants/products) in organic solvents, as well as the predominance of decomposition/polymerization reactions at rather high temperatures, requires the use of water-stable catalytic materials possessing high activity at low operating conditions.

In this regard, zeolites have been extensively investigated in the conversion of biobased feedstocks. The tunable acidity and shape selectivity of these tetrahedral oxides make these materials an attractive catalyst for biomass conversion. Several examples can be found in literature, such as in the aqueous/alcohol phase transformation of 1,3-dihydroxiacetone (DHA) to lactic acid/alkyl lactates [19], or in the conversion of bioderived sugars (e.g. cellulose, cellubiose, glucose, xylose) conversion to methyl levulinate[20,21] and furfural [22-26]. For more detailed information, the reader is kindly referred to recent excellent reviews on the use of zeolites in biomass processing [27,28]. In general, the state of the art on the matter evidences that zeolites traditionally employed in the petrochemical industry are not as effective in the conversion of biomass. In fact, contrary to fossil-feedstocks, lignocellulosic compounds often are bulky molecules presenting zeolite-poisoning elements such as $\mathrm{Na}^{+}$, whose intermediates are highly oxygenated unstable molecules often prone to decomposition, polymerization to humins, or coke formation due to the presence of acidic sites on the zeolites themselves. In fact, a higher Si/Al ratio (>15) compared to typical oil cracking zeolites ( $\mathrm{Si} / \mathrm{Al}$ ratio of ca. 6[29]) has shown better activity in biomass cracking, thanks to the right balance of Brønsted and Lewis Acid sites. Furthermore, zeolites micropores limit the diffusion of the biomass bulky structures, thus decreasing the effective surface area. One approach advanced by Lima et al. [30] was to swell and ultrasonicate layered aluminosilicates to achieve single crystalline sheets, obtaining a remarkable increase of the surface area and higher furfural yields. The same research group [31] also employed medium-large pore size SAPOs (silicoaluminophosphates) reporting satisfactory furfural yields (40-65\%), although in biphasic systems; furthermore, they investigated the delamination of ferrierite, $\mathrm{Nu}-6(2)$, and MCM-22 (ITQ-2) [32] obtaining higher yields thanks to better internal diffusion of substrates and products, emphasizing the need of fast diffusing catalytic systems to limit side-reactions. 
The deposition of metal nanoparticles might also tune the reactivity of a number of (alumino)silicates. For instance, our research group proposed a fine-tunable process in the conversion of starch into 5hydroxymethylfurfural (HMF) and furfural, or reduced products (5-methylfurfural and 5-methylfurfuryl alcohol) with Pd- and Cu-deposited Al-SBA-15 (with and without $\mathrm{Zn}$ in the support structure) and formic acid as hydrogen donating molecule [33]. In particular, $\mathrm{Cu} / \mathrm{Al}$-SBA was efficient in the selective production of HMF (ca. $70 \mathrm{~mol} \%$ ) under only 5 minutes of microwave irradiation, while Pd-based aluminosilicate possessed a higher hydrogenation activity favoring the aforementioned reduced products (Figure 3).

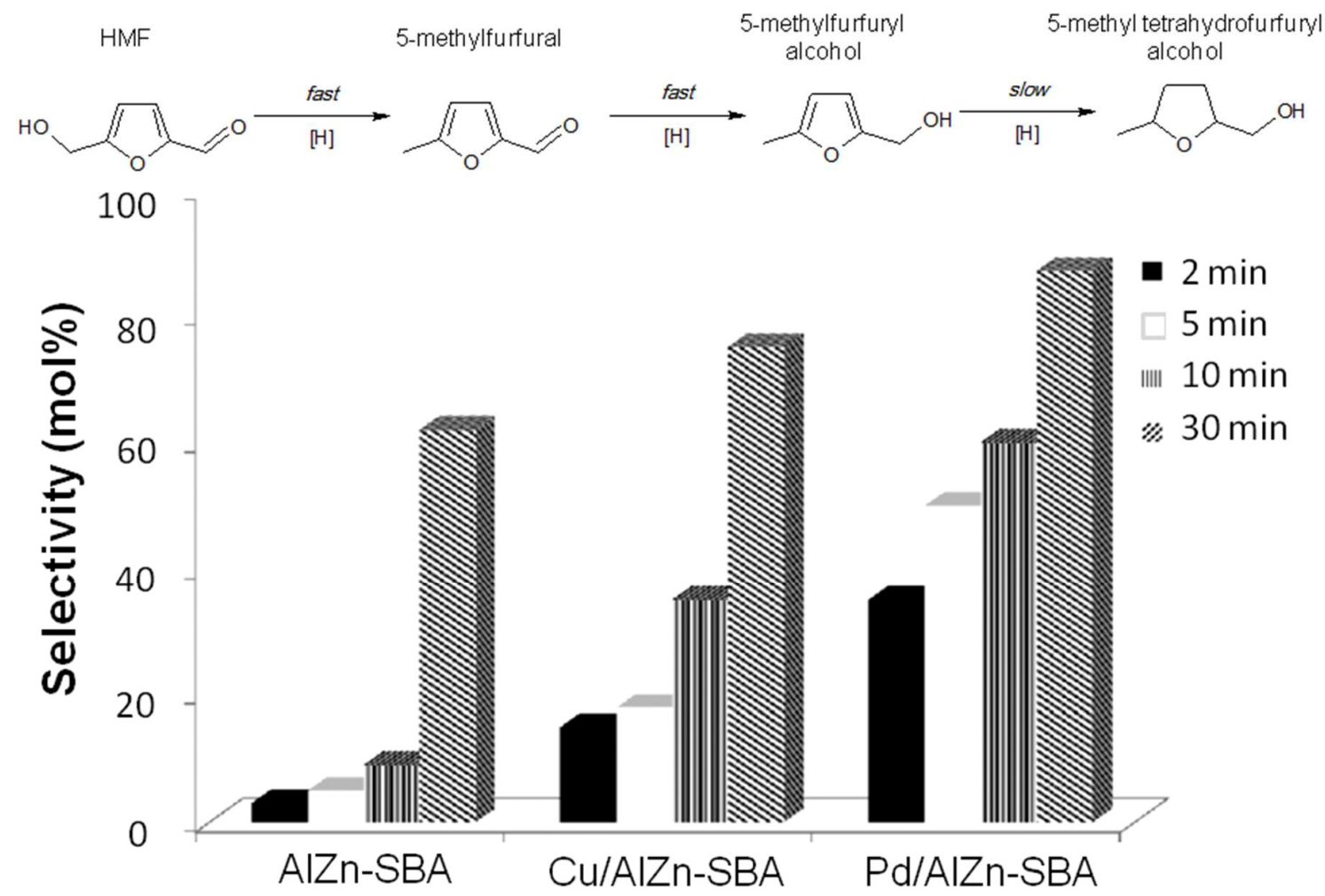

Figure 3. Selectivity to reduced products at different reaction times in the microwave-assisted conversion of starch. Adapted from reference 33.

Formic acid is not only a satisfactory hydrogen donor, but also an economical biomass-derived molecule, as it is a by-product of the industrial production of levulinic acid [34,35]. In fact, formic acid-mediated microwave irradiation with (noble) metal-supported aluminosilicates was also an effective approach in the 
catalytic decomposition of lignin. The NanoVal research group [36-39] investigated noble (Pd, Pt, Ru, Rh) and transitions metals $(\mathrm{Ni}, \mathrm{Cu})$ employing novel dry ball milling technique for superficial nanoparticles deposition on aluminosilicates it could be rather surprising that transition metal, $\mathrm{Ni}$, gave the optimal depolymerization results under microwave and mild reaction conditions $\left(<30 \mathrm{~min},<150{ }^{\circ} \mathrm{C}\right)$. In fact, the cheaper, more selective and water-stable Ni-based catalyst was found to have a better control of C-C and $\mathrm{C}-\mathrm{O}$ bond cleavage to simple aromatics (syringaldehyde, vanillin, aspidinol, desaspidinol). In fact, at the same metal loading ( $2 \mathrm{wt} \%$ ), noble metals (particularly Pd) favored the formation of a biochar, while $\mathrm{Ni}$ yielded to higher bio-oil (Figure 4).

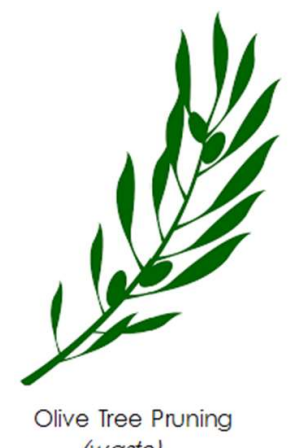

(waste)

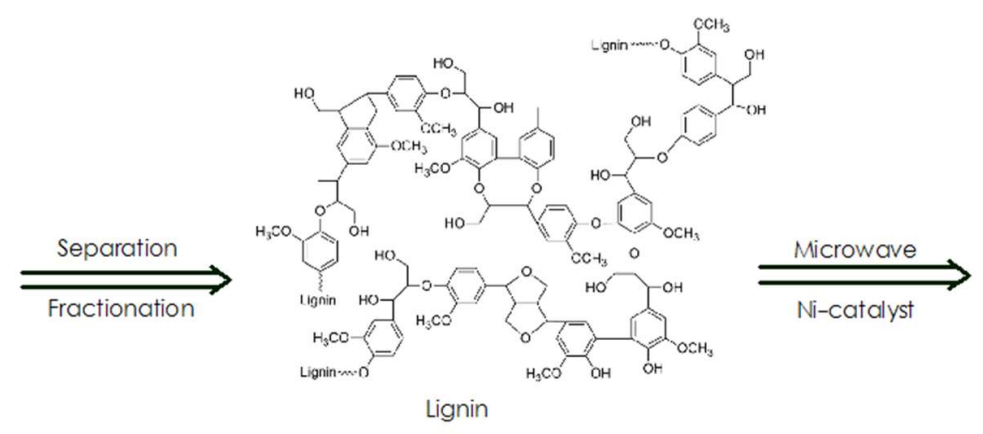

Lignin

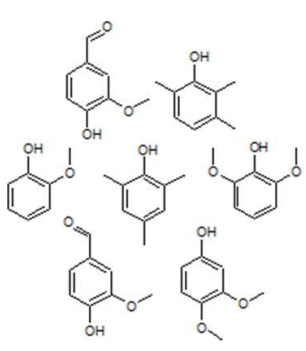

Simple Aromatics

Figure 4. Microwave-assisted decomposition of olive-tree extracted lignin into simple aromatics. Adapted from reference 36 .

This was further advanced in the recent studies conducted by Milovanovic [40,41] on NiO-containing zeolites (namely H-ZSM-5, H-BETA, H-Y) on the depolymerization of various lignocellulosic feedstocks, i.e. Biolignin ${ }^{\mathrm{TM}}$, Eucalyptus, hardwood lignings, birch and aspen woods. These are inevitable signs that cheaper and more abundant catalytic systems might be advantageous in biomass processing. In fact, the high reactivity of noble metals might be counterproductive: coke formation and side reactions (polymerization/decomposition) are enhanced, thus decreasing the overall atom economy of the process.

Formic acid, in combination of another hydrogen donor (i.e. 2-propanol, IPA), was found effective in the hydrothermal liquefaction of another recalcitrant biomass by-product: humins. In fact, the work of Heeres 
and coworkers elucidated how formic acid yields to higher partial hydrogen pressure in autoclaves at the start of the reaction as opposed to molecular hydrogen, thus leading to higher degree of humins depolymerization [42]. Moreover, when dealing with polymeric materials prone to recombination by condensation/hydrolysis (both acid-catalyzed reactions), neutral supports such as carbon (as opposed to acidic, e.g. alumina) were found more active in the recovery of monomeric compounds [42-44]. These findings further prove that typical petroleum catalytic converters, often based on acidic properties of the supports, may be less efficient due to the high polymerization activity of the oxygenated bio-feedstocks.

High residence times of lignocellulosic feedstocks/products in reaction media allow the predominance of side-reactions (such as the polymerization to humin by-products), especially at high temperatures and acid concentrations [45-49]. The use of microwave systems often allows a remarkable decrease of residence times. In fact, high temperatures and pressures in lab-scale sealed vessel (ca. $2 \mathrm{~mL}$ ) can be obtained in the seconds-to-minutes scale, whereas comparable conventional heating batch systems may require hours. It might be debated that microwave systems are not feasible at an industrial level for liquid media processing, due to the inability of the microwaves to penetrate in-depth large reactor volumes. One approach advanced by Kappe's research group [50,51] is to convert batch microwave reactors into micro/mesofluidic flow devices fitted with a back-pressure regulator, granting a scalable device by stacking.

Continuous flow might allow a better processing of lignocellulosic biomass and its consequent industrialization. In fact, continuous flow reactors allow not only a better control of reaction conditions, but also can be linearly scaled-up with easier process design, and catalyst regeneration/substitution. Furthermore, the possible extreme reduction of contact/residence time of the stream on the catalytic bed at higher space velocities of biomass feedstocks can suppress side-reactions by limiting collisions between molecules, and decreasing the build up of elimination molecules (e.g. $\left.\mathrm{CO}_{2}, \mathrm{H}_{2} \mathrm{O}\right)$ in the reactor. For instance, continuous flow processing was found to be advantageous in the conversion of ethanol to platform molecule 1,3-butadiene [52-55], which could then be translated to the conversion of plant-derived bioethanol [56] 
obtaining a renewable $\mathrm{C}_{4}$-alkene. Nonetheless, the low yields and selectivities of synthesizing petroleumlike molecules from biomass (i.e. olefins) is a signal that a shift from fossil-mimicking feeds is needed.

The continuous flow processing of whole biomass, on the other hand, might be challenging as more recalcitrant fractions/products (i.e. lignin/humins) are prone to plug orifices and valves of the system. A review on continuous hydrothermal liquefaction of biomass is given by Jones et al. [57], while an interesting and recent literature example of continuous flow processing is given by the conversion of of Chlorella microalgae to biofuels with a Pd-supported bacterial biomass catalyst [58]. Strategies to avoid plugging might include extreme dilution of the liquid feed or short contact times at elevated temperatures.

As whole lignocelluloses might plug continuous flow reactors, prior conversion of biomass to one of the identified platform chemicals (e.g. furfural) might represent an easier approach. Our research group has advanced quite a few investigations in the hydrogenation of furfural under continuous flow conditions. A recent work by Ouyang et al. investigated both commercial and mechanochemically-synthesized Pd and Pt catalysts on various supports, peculiarly with a magnetically separable Fe-doped SBA-15 in the continuous flow conversion of furfural. Pd-based catalysts were found more active in the production of reduced compounds (Figure 5), i.e. tetrahydrofurfuryl alcohol, while Pt yielded to the aromatic counterpart, furfuryl alcohol [59].

The higher activity of Pd-based catalysts was also observed in an earlier research as opposed to Rusupported catalysts [60], and further confirmed with Pd catalysts synthesized in flow [61]. In the totality of these works, neutral supports such as carbon were again found more stable and active as opposed to the aluminosilicates, while higher loadings of noble metals yielded to further hydrogenated and ring-opening products. These are inevitable signs that a shift towards cheaper and more abundant (i.e. carbon) catalytic systems is favorable when dealing with biomass processing. Consequently, the next paragraph will be centered on the cheapest catalytic materials: biomass-derived catalysts. 


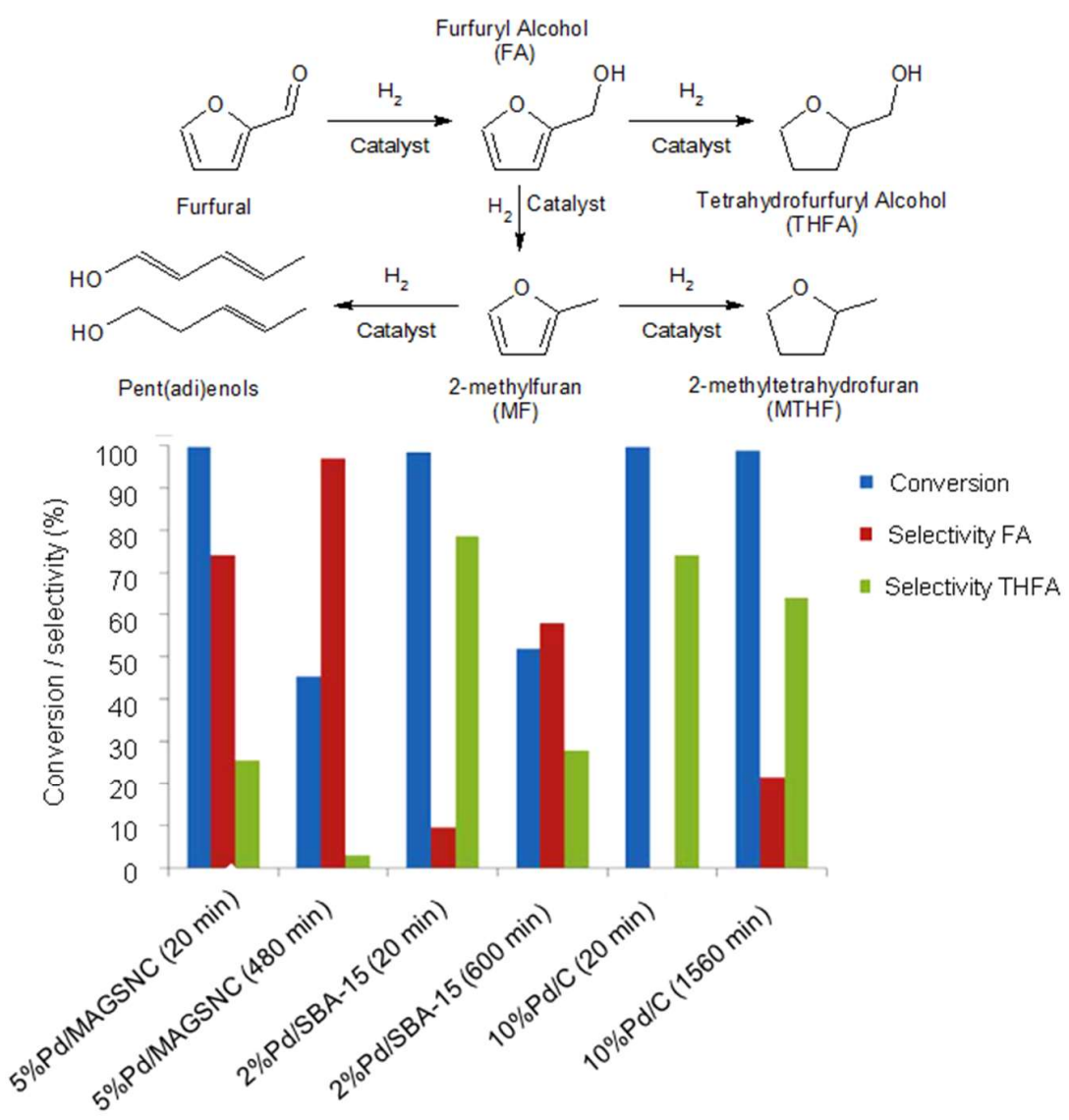

Figure 5. Activities of Pd-based catalysts in the continuous flow conversion of furfural. Adapted from reference 59 .

\section{Biomass Conversion for Catalytic Materials}

A catalyst is industrially efficient when it is sufficiently active and stable to justify the costs of synthesis over a lengthy period of time, reducing production delays in the substitution/regeneration of the catalytic material. Particularly, a water-stable, porous, and selective catalyst (i.e. tuned acidity and functionality) is required when dealing with biomass processing.

Porous carbon materials have been attracting the attention of the scientific community thanks to their outstanding surface areas (e.g. $>1000 \mathrm{~m}^{2} / \mathrm{g}$, activated carbon), tunable porosity, water/acid/base resistance, abundant (hence, economical), good regenerability, different densities, (e.g. diamond [62]> graphite 
[63] $>3$ D graphene [64] $>$ multiwalled carbon nanotubes [65] $\geq$ foams [66]), structures (Figure 6), and their tunable and reactive functional groups. In fact, carbon materials have been found possessing catalytic activities comparable to metal catalysts [67,68]. An excellent density functional theory study [69] also supports the high activity of oxygen-containing functionalities, such as quinone and lactone groups.

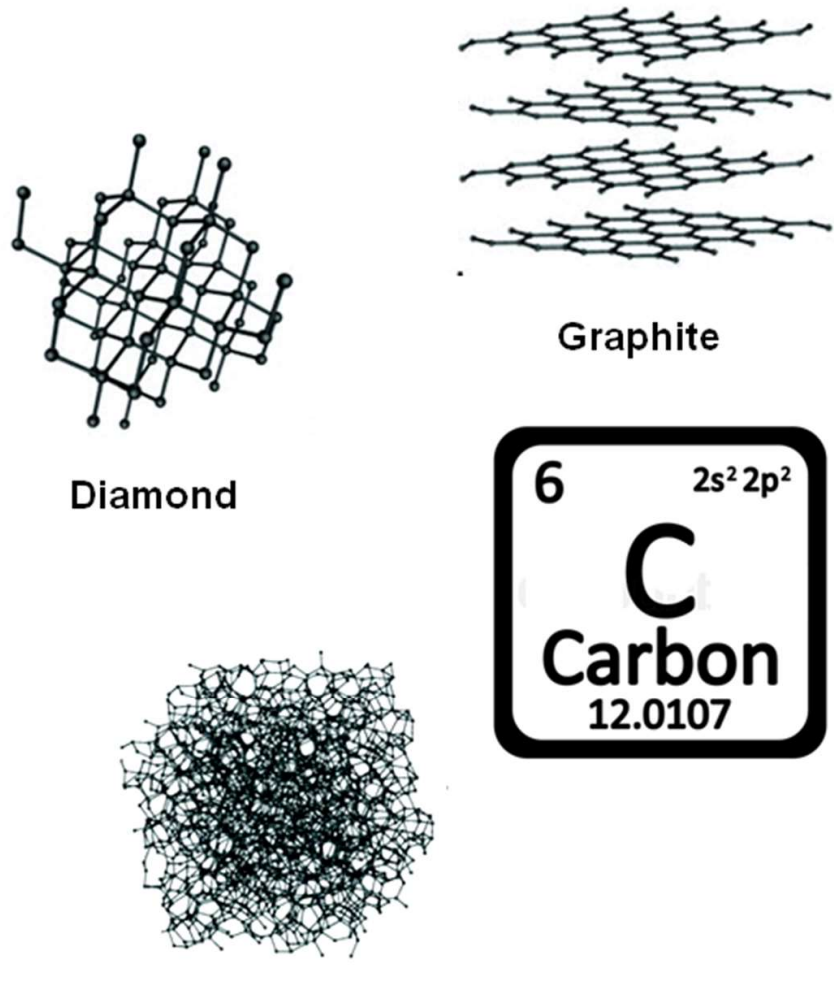

Amorphous Carbon

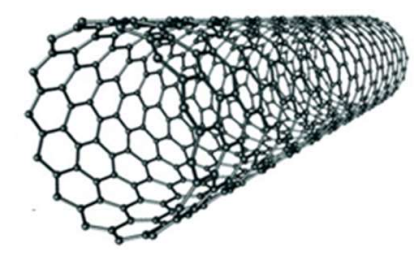

Carbon Nanotube

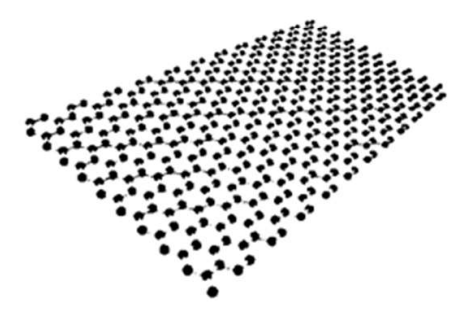

Graphene

Figure 6. Different allotropes and structures of carbon.

Traditionally, carbon materials were praised for their chemical inertness, being used as a support for metal (typically, noble) nanoparticles [70]. Often these carbon supports would be synthesized from the pyrolysis/chemical vapor deposition/laser ablation of fossil feedstocks obtaining $\mathrm{sp}^{2}$ hybridized carbon atoms, i.e. graphitic [71-74]. In particular, inorganic and organic carbon nanotubes (CNT) have attracted an enormous interest in the past few decades thanks to their electronic, mechanical, and structural properties 
$[75,76$.$] . These materials were often functionalized (e.g. with acid or bases) to achieve effective functional$ groups (e.g. lactone, carboxylic acid, ketone, anhydride, hydroxyl), thus higher reactivities [77]. However, the environmental concern of the starting materials, as well as the expensive equipment for the synthesis (e.g. chemical vapor deposition), has pushed the scientific community towards new strategies in the production of active carbon-based materials.

Along these lines, graphene oxide has been investigated as a cheaper alternative in the synthesis of graphene-like materials, as it is a by-product from graphite oxidation $[78,79]$. The reduction of graphene oxide (i.e. reduced graphene oxide, rGO) yields to materials that are structurally similar to pristine graphene, hence with high electric conductivity thanks to the $\mathrm{sp}^{2}$ hybridization. These modifications show the possibility of down-tuning oxygen functionalities of carbon materials, if needed. Full graphitization is often difficult to achieve, although resulting beneficial. In fact, rGO might present residual oxygen functionalities and defective edges that have actually been recognized as catalytically active sites [80-82].

Depositions of metals on rGO have shown enhanced activities for many catalytic reactions, e.g. in the electrocatalytic oxygen reduction [83], photoelectrochemical hydrogen productions [84,85], and catalytic oxidations $[86,87]$. In our research group, Franco et al. have recently demonstrated the catalytic activity of mechanochemically synthesized Fe- and Co-supported rGO in the oxidative cleavage of lignin model compound (isoeugenol) to vanillin, with yields of $38 \%$ over $1 \% \mathrm{Fe} / \mathrm{rGO}$ under conventional heating [88] or $45 \%$ if doped with $\mathrm{Nb}$ [89]. In a similar work from Bohre et al. [86] a synergistic effect between the metal and the support was evidenced in the selective oxidation of isoeugenol over Co/rGO. In fact, experimental runs with the two separate components showed extremely low catalytic activity, thus suggesting a positive effect of the carbon's residual oxygen functionalities on the Co nanoparticles. A recent work from Lee and Hong [90] also supports the enhanced catalytic activity of doped rGO (in particular, $\mathrm{Cr}^{3+}, \mathrm{Fe}^{3+}$, and $\left.\mathrm{Co}^{3+}\right)$ in the photocatalytic oxidation of cysteine. Similar conclusions were obtained in our recent work in the isoeugenol selective oxidative cleavage with humins/iron oxides nanocomposites (vide infra) [91]. 
A very recent and excellent review by Garcia et al. [92] showcases the active sites of graphene-based materials, which includes $\mathrm{N}$ and P-dopants, defects/vacancies, sulfur groups, and, in particular, oxygen functionalities. In fact, catalytic activity of carbon-based materials is often related to the presence of superficial oxygen functionalities, which can be classified into acidic and basic groups [93,94]. As explained above, biomass is an oxygen-rich carbon material that can thus offer the O-containing functionalities for catalysis. For instance, soil-, peat-, and water-derived humic/fulvic substances were found active in a number of condensation reactions $[95,96]$, supporting the use of biomass residues in the synthesis of carbon-based catalysts. By transferring the knowledge obtained on fossil-derived carbonaceous materials, biomass-derived carbon catalysts (or, support) can be indeed achieved.

Along these lines, many isolated carbohydrates, whole lignocelluloses, and wastes have been transformed to C-based catalytic systems via hydrothermal carbonization, template-directed synthesis, and controlled pyrolysis, to name a few $[97,98]$. Detailed ${ }^{13} \mathrm{C}-\mathrm{NMR}$ studies showed little-to-no difference in the hydrothermal carbonization of either sugars or whole biomass, suggesting the effective possibilities of using complex structures in creating carbon materials [99]. In particular, the group of Clark et al. pioneered the controlled carbonization of different polysaccharides (including starch, seaweed, pectin), with tunable chemical and surface properties ranging from hydrophilic to hydrophobic surfaces depending on temperature $\left(200-1000^{\circ} \mathrm{C}\right)$ with superlative mesoporosity $\left(\operatorname{Starbon}^{\circledR}\right)[100,101]$. This innovative synthesis of carbonaceous materials is based on an aqueous gel preparation of polysaccharides, a solvent exchange/drying step, finalized by the thermal carbonization at different temperatures (Figure 7). In particular, an increase in surface area, total pore volume, $\mathrm{C} / \mathrm{O}$ atomic ratios, and surface energy was obtained with increasing carbonization temperatures, increasing the carbon-like properties of these materials. 


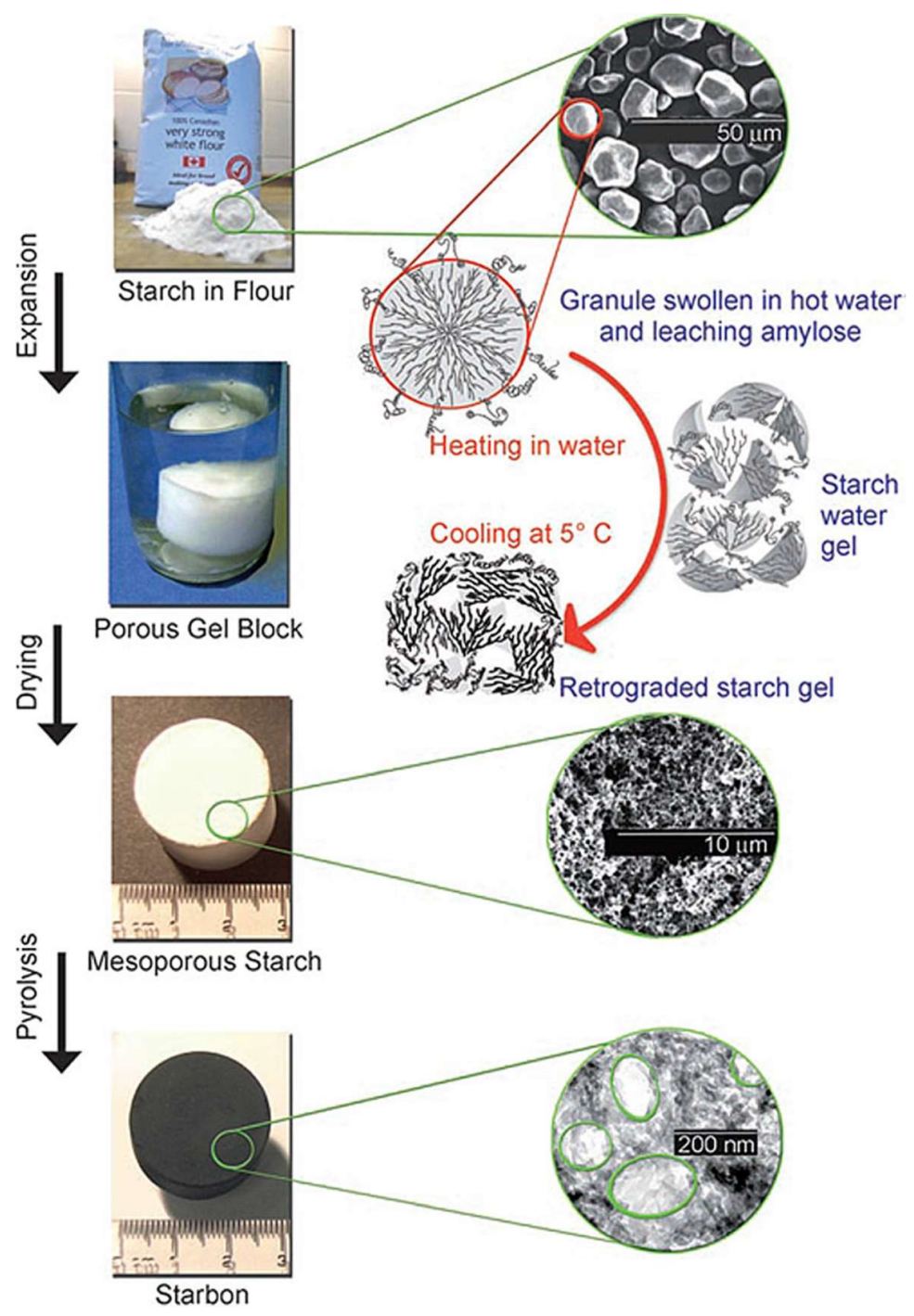

Figure 7. Synthetic steps in the formation of Starbon materials from starch. Adapted from reference 101.

In a similar manner, the NanoVal research group synthesized a magnetically separable starch-derived mesoporous carbon by the addition of $20 \mathrm{wt} \%$ magnetite nanoparticles (MAGBONS) [102]. These C-based materials (either sulfonated or not) showed promising activities in the microwave-assisted selective oxidation of benzyl alcohol, and dehydration of xylose to furfural, with desirable separation properties (i.e. magnetism). In particular, temperatures higher than $500{ }^{\circ} \mathrm{C}$ not only showed structural differences in Starbon materials [103], but also a loss of Magbons magnetic properties. Although this could be seen as a 
limitation, most of the biomass conversion reactions are run at lower temperatures, further confirming the importance of carbon-based catalytic systems.

Recent works from our group show our dedication in upgrading biomass/waste/by-products to carbonaceous systems for catalytic purposes in a variety of reactions. Ouyang et al. [104] have synthesized photocatalytically active wheat bran@ $\mathrm{TiO}_{2}$ via mechanochemical activation. In particular, $10 \%$ Ti-Bran yielded $22 \%$ of benzaldehyde at $33 \%$ conversion of benzyl alcohol, comparable to commercial $\mathrm{TiO}_{2}$. $\mathrm{By}$ using solventless mechanochemical activation of $\mathrm{Fe}$ or $\mathrm{Co}$ precursors in combination with: i) horse hemoglobin $(\mathrm{Hb})$ with a dopamine (DA) scaffold [105], ii) bovine serum albumin (BSA) and DA [106], and iii) polysaccharides (PS) [107] (Figure 8), Rodriguez-Padron et al. were able to synthesize biofunctionalized (magnetic) nanomaterials.

a) $\mathrm{FeCl}_{2} \cdot 4 \mathrm{H}_{2} \mathrm{O}$

b) $\mathrm{Fe}\left(\mathrm{NO}_{3}\right)_{3} \cdot 4 \mathrm{H}_{2} \mathrm{O}$, propionic acid

c) $\mathrm{FeCl}_{2} \cdot 4 \mathrm{H}_{2} \mathrm{O}$, titanium isopropoxide

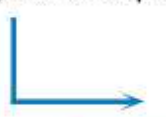

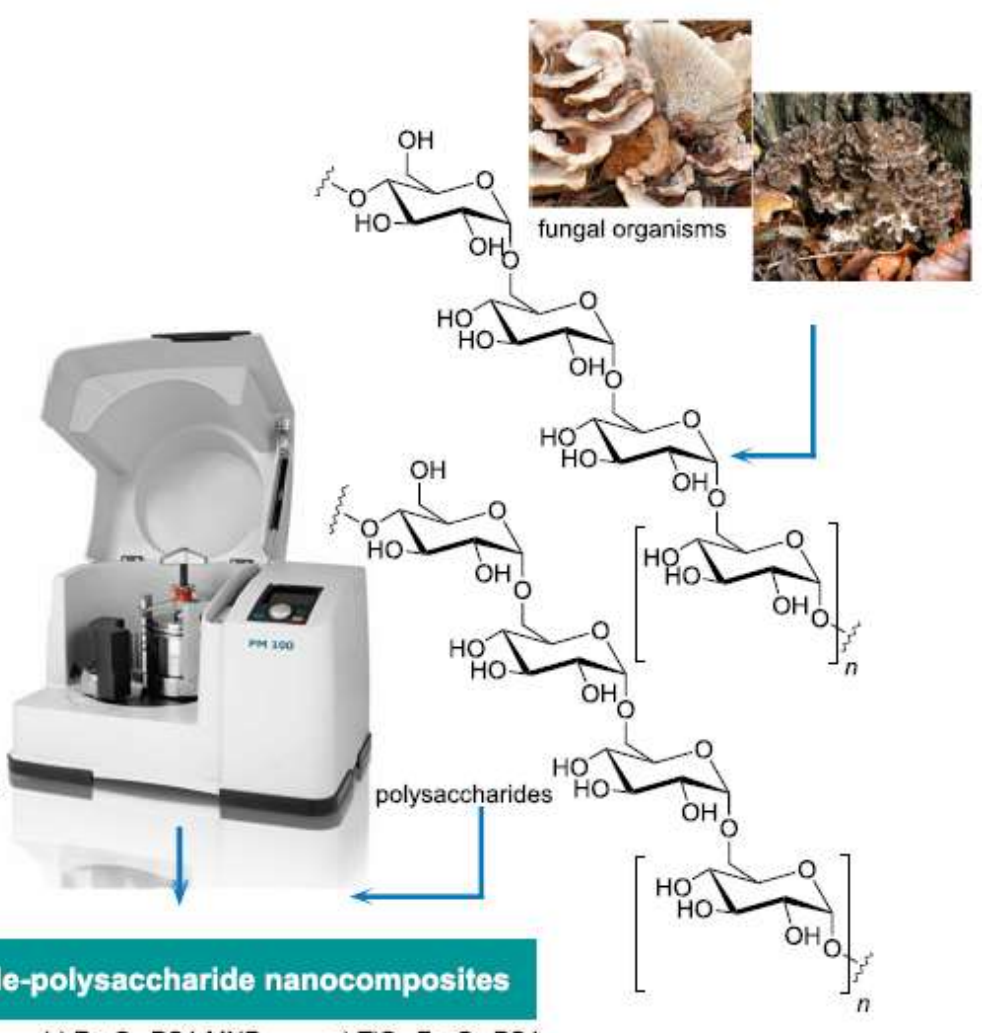

metal oxide-polysaccharide nanocomposites

a) $\mathrm{Fe}_{2} \mathrm{O}_{3}-\mathrm{PS} 4$

b) $\mathrm{Fe}_{2} \mathrm{O}_{3}-\mathrm{PS} 4-\mathrm{MNP}$

c) $\mathrm{TiO}_{2}-\mathrm{Fe}_{2} \mathrm{O}_{3}-\mathrm{PS} 4$

Figure 8. Synthetic scheme of metal oxide-carbon nanocomposites via the ball milling of polysaccharides and iron/titanium precursors. Adapted from reference 107. 
In particular, the plant-derived nanocomposites were found active in the selective oxidation of benzyl alcohol to benzaldehyde, where the optimal yield of benzaldehyde was obtained with a non-magnetic $\mathrm{Fe}_{2} \mathrm{O}_{3}$-PS nanomaterial. The latter nanocomposite also had comparable catalytic activity to the magnetic counterpart in the microwave-assisted alkylation of toluene after 3 minutes reaction, while the synthesized $\mathrm{TiO}_{2}-\mathrm{Fe}_{2} \mathrm{O}_{3}-\mathrm{PS}$ composite presented lower alkylation activity. Although not obvious from this work, a synergistic effect of earth abundant material, iron oxide, and carbon residues can be evidenced, in particular in oxidation reactions. In fact, our work on the use of iron oxide/humins nanocomposites in the microwaveassisted selective oxidation of isoeugenol's double bond to vanillin (Figure 9) in the presence of hydrogen peroxide under mild conditions $\left(<150{ }^{\circ} \mathrm{C}\right.$, autogenous pressure) [91] has drawn similar conclusions (supported also by Bohre et al. [84]).

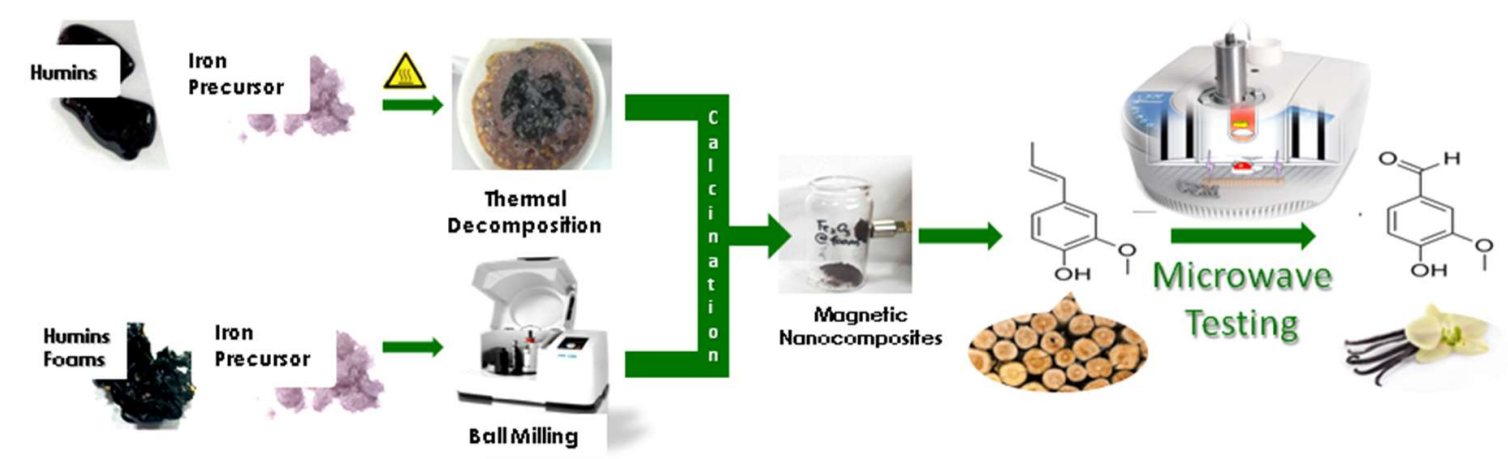

Figure 9. Flow diagram of the solvent-less synthesis of humins-based iron oxide catalytic nanocomposites, and their testing in the microwave-assisted selective oxidation of lignin model molecule, isoeugenol, to vanillin. Based on reference 91.

In particular, hematite iron oxide phase was found to play a crucial role in the oxidation reaction, although ineffective if not in the presence of oxygenated carbon (i.e. humin by-products residues). In fact, blank tests with commercial iron oxide nanopowders have shown little to no activity $(<30 \%)$ and selectivity $(<20 \%)$ in the conversion of lignin model-compound, isoeugenol. A more surprising finding is that thermally treated humins (i.e. foams [66]) were remarkably active ( $>90 \%$ conversion), although not selective $(<20 \%)$. These clues again support the assumption of exceptional oxidation activities of carbon presenting oxygen 
functionalities. Furthermore, the inorganic-organic hybridization protects the carbonaceous residues from oxidation as it was seen for carbon nanotubes [108], thus yielding to highly stable catalysts. These are inevitable signs that a shift towards cheaper and more abundant catalytic systems is possible when dealing with delicate reactions, and biomass processing.

\section{Conclusions}

The current petroleum-based economy may irreversibly change the Earth that we know by now. Scarcity of resources, raising $\mathrm{CO}_{2}$ levels, and pollution shall become the driving force for researchers to find renewable and eco-friendly fuels, chemicals, and materials. Biomass processing might be one of the biggest renewable economies of our future, thanks to its abundance, capacity to recycle $\mathrm{CO}_{2}$, and possibility of conversion to a plethora of platform chemicals. Its structural complexity and high presence of reactive functionalities still hinders its full utilization in the current economies.

Catalytic approaches based on traditional petrochemical processes have been proven partially effective in the conversion of biomass (e.g. zeolites). However, neutral supports such as carbon have been found overall promising in terms of activity, but also stability. Furthermore, traditional batch reactions cause high residence times of the molecules in the vessels, favoring recombination to high molecular weight byproducts that have yet to find applications (e.g. humins). In this regard, continuous flow processing of biomass might be advantageous thanks to the possibility of remarkably decreasing the contact time between the catalyst and reactants.

Carbon-based materials deserve to be investigated further, owed to its synergistic effect with metal nanoparticles or oxides resulting in enhanced catalytic activity. In particular, oxygen functionalities in the carbon supports play a crucial role in stabilizing active metals as well as being catalytically active in a number of reactions, in particular selective oxidations. Thus, biomass-a highly oxygenated carbon materialmight be the most promising platform for the synthesis of carbon-based catalytic systems. 


\section{References}

[1] Chisholm, H., Ed. Encyclopedia Britannica, 11th ed.; Cambridge University Press, U.K., 1911.

[2] Milezzinoglu A. and M. L. Williams, Eds., Industrial Air Pollution, Springer-Verlag, Berlin, Germany, 1992.

[3] Fleeger, J.W.; Carman, K.R.; Nisbet, R.M. Sci. Total. Environ. 2003, 317, 207-233.

[4] Peterson, C.H.; Rice, S.D.; Short, J.W., Esler, D., Bodkin, J.L., Ballachey, B.E., Irons, D.B. Science 2003, 302. 2082-2086.

[5] Hornbach, M.J.; DeShon, H.R.; Ellsworth, W.L.; Stump, B.W.; Hayward, C.; Frohlich, C.; Oldham, H.R.; Olson, J.E.; Magnani, M.B.; Brokaw, C.; Luetgert, J.H. Nat. Commun. 2015, 6, 1-11.

[6] National Research Council, Induced Seismicity Potential in Energy Technologies, The National Academies Press, Washington, DC, USA, 2013.

[7] Earth's CO2-Are we stabilizing yet? https://www.co2.earth/ (accessed Oct 25, 2017).

[8] Renewable Energy: Bioenergy.

http://ec.europa.eu/research/energy/index.cfm?pg=area\&areaname=renewable_bio (accessed Oct 25, 2017).

[9] Obermeier, W.A.; Lehnert, L.W.; Kammann, C.I.; Müller, C.; Grünhage, L.; Luterbacher, J.; Erbs, M.; Moser, G.; Seibert, R.; Yuan, N.; Bendix, J. Nat. Clim. Change 2017, 7, 137-141.

[10] Wu, L.; Moteki, T.; Gokhale, A.A.; Flaherty, D.W.; Toste, F.D. Chem 2016, 1, 32-58.

[11] Filiciotto, L.; Balu, A.M.; van der Waal, J.C.; Luque, R. Catal. Today 2017, In press, https://doi.org/10.1016/j.cattod.2017.03.008.

[12] Tang, X.; Sun, Y.; Zeng, X.; Hao, W.; Lin, L.; Liu, S. Energy Fuels, 2014, 28, 4251-4255. 
[13] Von Hebel, K. L.; Lange, J.-P. Process for Liquefying a Cellulosic Material. Patent WO/2011/141545, Nov 17, 2011.

[14] “Top Value Added Chemicals from Biomass: I. Results of Screening for Potential Candidates from Sugars and Synthesis Gas” Werpy, T.A.; Holladay, J.E.; White, J.F. US Department of Energy, 2004, USA. http://www.eere.energy.gov/biomass/pdfs/35523.pdf(accessed Oct 25, 2017).

[15] Bozell, J.J.; Petersen, G.R. Green Chem. 2010, 12, 539-554.

[16] Rose, M.; Palkovits, R. Macromol. Rapid Commun. 2011, 32, 1299-1311.

[17] Avantium, https://www.avantium.com (accessed October 25, 2017).

[18] Synvina, https://www.synvina.com (accessed October 25, 2017).

[19] Morales, M.; Dapsens, P.Y.; Giovinazzo, I.; Witte, J.; Mondelli, C.; Papadokonstantakis, S.; Hungerbuhler, K.; Perez-Ramirez, J. Energy Environ. Sci. 2015, 8, 558-567.

[20] Saravanamurugan, S.; Riisager, A. ChemCatChem 2013, 5, 1754-1757.

[21] Garves, K. Preparation of Alkoxymethylfurfurals and Alkyl Levulinates from Cellulose or Lignocelluloses or Starches and Alcohols, Patent DE3621517, Jan 7, 1988.

[22] Moreau, C.; Durand, R.; Peyron, D.; Duhamet, J.; Rivalier, P. Ind. Crops Prod., 1998, 7, 95-99.

[23] Bruce, S.M.; Zong, Z.; Chatzidimitriou, A.; Avci, L.E.; Bond, J.Q.; Carreon, M.A.; Wettstein, S.G. J. Mol. Catal. A: Chem. 2016, 422, 18-22.

[24] Lessard, J.; Morin, J.-F.; Wehrung, J.-F.; Magnin, D.; Chornet, E. Top. Catal. 2010, 53, 12311234.

[25] O’Neill, R.; Ahmad, M.N.; Vanoye, L.; Aiouache, F. Ind. Eng. Chem. Res. 2009, 48, 4300-4306. 
[26] Kim, S.B.; You, S.J.; Kim, Y.T.; Lee, S.; Lee, H.; Park, K.; Park, E.D. Korean J. Chem. Eng. 2011, 28, 710-716.

[27] Li, H.; Yang, S.; Riisager, A.; Pandey, A.; Sangwan, R.S.; Saravanamurugan, S.; Luque, R. Green Chem., 2016, 18, 5701-5735.

[28] Ennaert, T.; van Aelst, J.; Dijkmans, J.; de Clercq, R.; Schutyser, W.; Dusselier, M.; Verboekend, D.; Sels, B.F. 2016, 45, 548-611.

[29] Corma, A.; Martínez, A. Stud. Surf. Sci. Catal. 2005, 157, 337-366.

[30] Lima, S.; Pillinger, M.; Valente, A.A. Catal.Comm. 2008, 9, 2144-2148.

[31] Lima, S.; Fernandes, A.; Antunes, M.M.; Pillinger, M.; Ribeiro, F.; Valente, A.A. Catal. Lett. 2010, $135,41-47$.

[32] Antunes, M.M.; Lima, S.; Fernandes, A.; Pillinger, M.; Ribeiro, M.F.; Valente, A.A. Appl. Catal. A: Gen. 2012, 417, 243-252.

[33] Yepez, A.; Garcia, A.; Climent, M.S.; Romero, A.A.; Luque, R. Catal. Sci. Technol. 2014, 4, 428-434.

[34] Heeres, H.; Handana, R.; Chunai, D.; Rasrendra, C.B.; Girisuta, B.; Heeres, H.J. Green Chem., 2009, 11, 1247-1255.

[35] Deng, L.; Li, J.; Lai, D.M.; Fu, Y.; Guo, Q.X. Angew. Chem. Ind. Ed. 2009, 48, 6529-6532.

[36] Toledano, A.; Serrano, L.; Pineda, A.; Romero, A.A.; Labidi, J.; Luque, R. Appl. Catal. B: Environ. 2014, 145, 43-55.

[37] Toledano, A.; Serrano, L.; Labidi, J.; Balu, A.M.; Pineda, A.; Luque, R. ChemCatChem 2013, 5, 977-985. 
[38] Toledano, A.; Serrano, L.; Pineda, A.; Balu, A.M.; Luque, R.; Labidi, J. ChemSusChem 2013, 6, $529-536$.

[39] Pineda, A.; Balu, A.M.; Campelo, J.M.; Romero, A.A.; Carmona, D.; Balas, F.; Santamaria, J.; Luque, R. ChemSusChem 2011, 4, 1561-1565.

[40] Milovanovic, J.; Luque, R.; Tschentscher, R.; Romero, A.A.; Li, H.; Shih, K.; Rajic, N. Biomass Bioenergy 2017, 103, 29-34.

[41] Milovanovic, J.; Rajic, N.; Romero, A.A.; Li, H.; Tschentscher, R.; Luque, R. ACS Sustain. Chem. Eng. 2016, 4, 4305-4313.

[42] Wang, Y.; Agarwal, S.; Kloekhorst, A.; Heeres, H.J. ChemSusChem 2016, 9, 951-961.

[43] Wang, Y.; Agarwal, S.; Tang, Z.; Heeres, H.J. RSC Adv. 2017, 7, 5136-5147.

[44] Wang, Y.; Agarwal, S.; Heeres, H.J. ACS Sustain. Chem. Eng. 2017, 5, 469-480.

[45] Zhang, L.; Xi, G.; Zhang, J.; Yu, H.; Wang, X. 2017, 224, 656-661.

[46] Oladi, S.; Aita, G.M. Ind. Crops Prod. 2017, 103, 122-132.

[47] Jeong, H.; Park, Y.-C.; Seong, Y.-J.; Lee, S.M. Bioresour. Technol. 2017, 245, 351-357.

[48] Tsilomelekis, G.; Orella, M.J.; Lin, Z.; Cheng, Z.; Zheng, W.; Nikolakis, V.; Vlachos, D.G. Green Chem. 2016, 18, 1983-1993.

[49] Hu, X.; Lievens, C.; Li, C.-Z ChemSusChem 2012, 5, 1427-1434.

[50] Glasnov, T.N.; Kappe, C.O. Chem. Eur. J. 2011, 17, 11956-11968.

[51] Damm, M.; Glasnov, T.N.; Kappe, C.O. Org. Process Res. Dev. 2010, 14, 215-224. 
[52] Chung, S.-H.; Angelici, C.; Hinterding, S.O.M.; Weingarth, M.; Baldus, M.; Houben, K.;

Weckhuysen, B.M.; Bruijnincx, P.C.A. ACS Catal. 2016, 6, 4034-4045.

[53] Angelici, C.; Velthoen, M.E.Z.; Weckhuysen, B.M.; Bruijnincx, P.C.A. Catal. Sci. Technol. 2015, 5, 2869-2879.

[54] Angelici, C.; Velthoen, M.E.Z.; Weckhuysen, B.M.; Bruijnincx, P.C.A. ChemSusChem 2014, 7, 2505-2515.

[55] Angelici, C.; Meirer, F.; van der Eerden, M.J.; Schaink, H.L.; Goryachev, A.; Hofmann, J.P.; Hensen, E.J.M.; Weckhuysen, B.; Bruijnincx, P.C.A. ACS Catal. 2015, 5, 6005-6015.

[56] Angelici, C.; Weckhuysen, B.M.; Bruijnincx, P.C.A. ChemSusChem 2013, 6, 1595-1614.

[57] Elliot, D.C.; Biller, P.; Ross, A.B.; Schmidt, A.J.; Jones, S.B. Bioresour. Technol. 2015, 178, $147-156$.

[58] Kunwar, B.; Deilami, S.D.; Macaskie, L.E.; Wood, J.; Biller, P.; Sharma, B.K. Fuel 2017, 209, $449-456$.

[59] Ouyang, W.; Yepez, A.; Romero, A.A.; Luque, R. 2017, In Press, http://dx.doi.org/10.1016/j.cattod.2017.07.011.

[60] Garcia-Olmo, A.J.; Yepez, A.; Balu, A.M.; Romero, A.A.; Li Y.; Luque, R. 2016, 6, 4705-4711.

[61] Garcia-Olmo, A.J.; Yepez, A.; Balu, A.M.; Prisen, P.; Garcia, A.; Maziere, A.; Len, C.; Luque, R. Tetrahedron 2017, I73I, 5599-5604.

[62] "Diamond", https://www.mindat.org/min-1282.html (accessed Oct 25, 2017).

[63] “Graphite", https://www.mindat.org/min-1740.html (accessed Oct 25, 2017).

[64] Qin, Z.; Jung, G.S.; Kang, M.J.; Buehler, M.J. Sci. Adv. 2017, 3, no. 1, e1601536. 
[65] Lehman, J.H.; Terrones, M.; Mansfield, E.; Hurst, K.E.; Meunier, V. Carbon 2011, 49, 25812602.

[66] Mija, A.C.; de Jong, E.; van der Waal, J.C.; van Klink, G.P.M. Humins-containing foam, Patent WO 2017074183 A8, Jun 22, 2017.

[67] Machado, B.F.; Serp, P. Catal. Sci. Technol. 2012, 2, 54-75.

[68] Dreyer, R.; Park, S.; Bielawski, C.W.; Ruoff, R.S. Chem. Soc. Rev. 2010, 39, 228-240.

[69] Li, B.; Su, D. Chem. Eur. J. 2014, 20, 7890-7894.

[70] Garrido, E.; Aymonier, C.; Roiban, L.; Ersen, O.; Labrugere, C.; Gaillard, P.; Lamirand-Majimel, M. J. Supercrit. Fluids 2015, 101, 110-116.

[71] Mattevi, C.; Kima, H.; Chhowalla, M. J. Mater. Chem. 2011, 21, 3324-3334.

[72] Li, X.; Cai, W.; An, J.; Kim, S.; Nah, J.; Yang, D.; Piner, R.; Velamakanni, A.; Jung, I.; Tutuc, E.; Banerjee, S.K.; Colombo, L.; Ruoff, R.R. Science 2009, 324, 1312-1314.

[73] Novoselov, K.S.; Geim, A.K.; Morozov, S.V.; Jiang, D.; Zhang, Y.; Dubonos, S.V.; Grigorieva, I.V.; Firsov, A.A. Science 2004, 306, 666-669.

[74] Rodriguez-Reinoso, F. Carbon 1998, 36, 159-175.

[75] Tasis, D.; Tagmatarchis, N.; Bianco, A.; Prato, M. Chem. Rev. 2006, 106, 1105-1136.

[76] Allen, M.J.; Tung, V.C.; Kaner, R.B. Chem. Rev. 2010, 110, 132-145.

[77] Chen, Y.; Haddon, R.C.; Fangm, S.; Rao, Am.M.; Eklund, P.C.; Lee, W.H.; Dickey, E.C.; Grulke, E.A.; Pendergrass, J.C.; Chavan, A.; Haley, B.E.; Smalley, R.E. J. Mater. Res. 1998, 13, 24234231. 
[78] Mao, S.; Pu, H.; Chen, J. RSC Adv. 2012, 2, 2643-2662.

[79] Dreyer, D. R.; Park, S.; Bielawski, C. W.; Ruoff, R. S. Chem. Soc. Rev. 2010, 39, 228-240.

[80] Navalon, S.; Dhakshinamoorthy, A.; Alvaro, M.; Garcia, H. Chem. Rev. 2014, 114, 6179-6212.

[81] Peng, W.; Liu, S.; Sun, H.; Yao, Y.; Zhi, L.; Wang, S. J. Mater. Chem. A 2013, 1, 5854-5859.

[82] Frank, B.; Zhang, J.; Blume, R.; Schlçgl, R.; Su, D.S. Angew. Chem. Int. Ed. 2009, 48, 69136917.

[83] Joo, Y.; Ahmed, M.S.; Han, H.S.; Jeon, S. Int. J. Hydrog. Energy 2017, 42, 21751-21761.

[84] Fan, W.; Yu, X.; Lu, H.C.; Bai, H.; Zhang, C.; Shi, W. Appl. Catal. B: Environ. 2016, 181, 7-15.

[85] Babu, S.G.; Vinoth, R.; Kumar, D.P.; Shankar, M.V.; Chou, H.L.; Vinodgopal, K.; Neppolian, B. Nanoscale 2015, 7, 7849-7857.

[86] Bohre, A.; Gupta, D.; Alam, I.; Sharma, R.K.; Saha, B. ChemistrySelect 2017, 2, 3129-3136.

[87] Sun, H.; Wang, Y.; Liu, S.; Ge, L.; Wang, L.; Zhu, Z.; Wang, S. Chem. Commun. 2013, 49, 99149916.

[88] Franco, A.; De, S.; Balu, A.M.; Garcia, A.; Luque, R. Beilstein J. Org. Chem. 2017, 13, 14391445.

[89] Franco, A.; De, S.; Balu, A.M.; Romero, A.A.; Luque, R. ChemistrySelect 2017, 2, 9546.9551.

[90] Lee, H.; Hong, J.A. Nanoscale Res. Lett. 2017, 12, 426.

[91] Filiciotto, L.; Balu, A.M.; Romero, A.A.; Rodriguez-Castellon, E.; van der Waal, J.C.; Luque, R. Green Chem. 2017, 19, 4423-4434. 
[92] Navalon, S.; Dhakshinamoorthy, A.; Alvaro, M.; Antonietti, M.; Garcia, H. Chem. Soc. Rev. 2017, 46, 4501-4529.

[93] Kvande, I.; Zhu, J.; Zhao, T. J.; Hammer, N.; Ronning, M.; Raaen, S.; Walmsley, J. C.; Chen, D., J. Phys. Chem. C 2010, 114, 1752-1762.

[94] Zhou, J.H.; Sui, Z.J.; Li, P.; Chen, D.; Dai, Y.C.; Yuan, W.K. Carbon 2006, 44, 3255-3262.

[95] Tang, W.W.; Zeng, G.M.; Gong, J.L.; Liang, J.; Xu, P.; Zhang, C.; Huang, B.B. Sci. Total. Environ. 2014, 468-468, 1014-1027.

[96] Klavins, M.; Dipane, J.; Babre, K. Chemosphere 2001, 44, 737-742.

[97] De, S.; Balu, A.M.; van der Waal, J.C.; Luque, R. ChemCatChem 2015, 7, 1608-1629.

[98] Gupta, G.K.; De, S.; Franco, A.; Balu, A.M.; Luque, R. Molecules 2016, 21 , 48.

[99] Baccile, N.; Laurent, G.; Babonneau, F.; Fayon, F.; Titirici, M.-M.; Antonietti, M. J. Phys. Chem. C 2009, 113, 9644-9654.

[100] White, R.J.; Budarin, V.; Luque, R.; Clark, J.H.; Macquarrie, D.J. Chem. Soc. Rev. 2009, 38, 3401-3418

[101] Budarin, V.; Clark, J.H.; Hardy, J.J.E.; Luque, R.; Milkowski, K.; Tavener, S.J.; Wilson, A.J. Angew. Chem. Int. Ed. 2006, 45, 3782-3786.

[102] Ojeda, M.; Balu, A.M.; Romero, A.A.; Esquinazi, P.; Ruokolainen, J.; Sixta, H.; Luque, R. ChemCatChem 2014, 6, 2847-2853.

[103] Shuttleworth, P.S.; Budatin, V.L.; Luque, R.; White, R.J.; Clark, J.H.; N’Gunko, V. Chem. Eur. J. 2013, 19, 9351-9357. 
[104] Ouyang, W.; Reina, J.M.; Kuna, E.; Yepez, A.; Balu, A.M.; Romero, A.A.; Colmenares, J.C.;

Luque, R. J. Environ. Manage. 2017, 203, 768-773.

[105] Rodriguez-Padron, D.; Puente-Santiago, A.R.; Caballero, A.; Benitez, A.; Balu, A.M.; Romero, A.A.; Luque, R. J. Mater. Chem. A 2017, 5, 16404-16411.

[106] Rodriguez-Padron, D.; Puente-Santiago, A.R.; Balu, A.M.; Romero, A.A.; Luque, R. Chem.

Commun. 2017, 53, 7635-7637.

[107] Rodriguez-Padron, D.; Balu, A.M.; Romero, A.A.; Luque, R. Beilstein J. Org. Chem. 2017, 13, 1982-1993.

[108] Aksel, S.; Eder, D. J. Mater. Chem. 2010, 20, 9149-9154. 